a long term decline or increase in the disability incidence rates. Over the 20th century, French male mortality rates declined substantially, and we would argue that it is quite implausible to assume that the mortality rates of disabled men would not have declined along with those of non-disabled men. In the French male population, life expectancy has not remained unchanged, and it is not reasonable to expect outflows from the disabled state to remain unchanged. We made the arbitrary assumption that the relative risk of death for disabled versus nondisabled people remained constant at 3.66 in the published simulations. We also carried out simulations where the relative risk ranged from 1 to 10 and also varied with age. We found that the results were not highly sensitive to the value assumed and did not affect our conclusions.

In response to criticism of the constant relative risk assumption, we have carried out additional simulations in which we assume that the ratio of the mortality risk for disabled male to the average mortality risk for all males remains constant at its value in the year 1945 , and so is independent of changes in disability prevalence. This had very little effect on the estimated health expectancies under any of the scenarios and confirms our published comment that the results are not highly sensitive to assumptions about the mortality rates for disabled people.

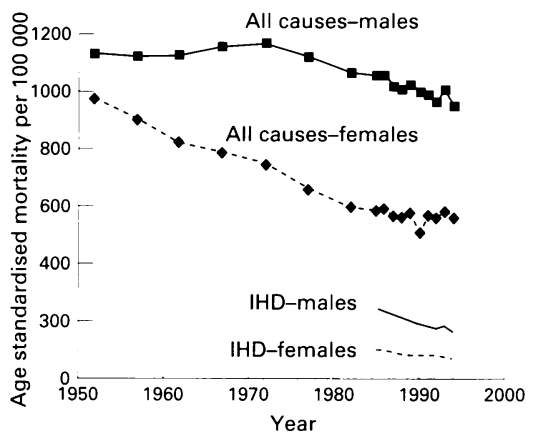

Figure 1 Trends in mortality from all causes and ischaemic heart disease, males and females, The Netherlands, 1952-94.

We intended no implication as to the plausibility of the scenario of Barendregt et al by describing it as a "hypothetical example"; that was the description they themselves used. $^{2}$ We have no disagreement with their scenario or its results, but repeat that such a simulation is not relevant to the question of how adequate Sullivan's method is for monitoring at the whole of population level. Thrombolytic therapy may well have been introduced in a three year period in The Netherlands, and may well have had a major effect on survival rates and a detectable effect on cardiovascular mortality at population level. Despite this, in-hospital or posthospital mortality after myocardial infarction does not account for most cardiovascular deaths (in Australia around $8.0 \%$ of myocardial infarction deaths occur outside hospital).

Figure 1 shows long term trends in mortality rates for The Netherlands for all causes mortality and ischaemic heart disease mortality. ${ }^{3}$ Rates are age standardised using the European standard population and five year averages are shown prior to 1985 . It is clear that the impact of thrombolytic therapy has not caused any sudden change in all cause mortality rates (the relevant rates for use with Sullivan's method) at the population level, and that Sullivan's method would be entirely adequate for monitoring long term trends in Dutch health expectancies. Very few changes in treatment practice would result in such dramatic changes in transition rates as the "hypothetical example" of Barendregt et al, and it is very unlikely that sudden changes in all causes mortality or disability transition rates at the population level will result from new medical interventions.

Finally, to the question of monitoring compression or expansion of morbidity. The example in the letter above is based on the assumption that compression ceases, allowing the disability prevalence in the population to reach its equilibrium value. We have no disagreement with the conclusion that in such a case the Sullivan's method would give a spurious compression-it is another example of the limitation of Sullivan's method when there are sudden changes in transition rates. In a more realistic example, where disability incidence and prevalence evolve smoothly, Sullivan's method will give a reasonably good indication of whether compression or expansion is occurring. In our published scenarios, Sullivan's method provides quite accurate estimates of the degree to which compression or expansion is occurring.

In conclusion, we do not believe we are in disagreement over the usefulness and limitations of Sullivan's method or that the example of Barendregt et al contradicts our conclusion that when population health is evolving reasonably smoothly, Sullivan's method is acceptable.

COLIN D MATHERS Australian Institute of Health and Welfare, Canberra, Australia

JEAN-MARIE ROBINE

Equipe INSERM Demographie et Sante, Montpellier, France

1 Mathers $\mathrm{CD}$, Robine J-M. How good is Sullivan's method for monitoring changes in population health expectancies? $f$ Epidemiol population health expectancies?

2 Barendregt JJ, Bonneux L, Van der Maas PJ. Health expectancy: an indicator for change? $\mathcal{f}$ Epidemiol Community Health 1994;48: 482-7.

World Health Organization. World Health Statistics Annuals 1986-1995. Geneva: WHO.

\section{Smoking and Alzheimer's disease: an alternative hypothesis}

Sir-Many studies have been carried out identifying risk and protective factors for Alzheimer's disease, often with conflicting results. This particularly applies to smoking. While some, such as the case-control studies from the MRC elderly hypertensive trial ${ }^{1}$ and the Canadian study of health and aging, ${ }^{2}$ have shown no significant effect of smoking, others, including studies in The Netherlands ${ }^{3}$ and America, ${ }^{4}$ have reported that the prevalence of Alzheimer's disease was significantly lower in smokers than non-smokers. It has been suggested that the mode of action might be via nicotine. ${ }^{3}$ Paradoxically, Brennera et $a l^{4}$ also found that the protective effect was most marked at low dose exposure to cigarettes, but disappeared in those with the highest pack years exposure. van Duijn and Hofman, however, found an inverse relation between the number of cigarettes smoked and the reduction in Alzheimer's disease cases. The Canadian study ${ }^{2}$ also confirmed the findings of other workers that the odds ratios for suf- fering from Alzheimer's disease were lower in subjects with a history of arthritis or of nonsteroidal anti-inflammatory (NSAIDS) drug use.

Could these observations be linked? In a paper published in the European fournal of Public Health in September, ${ }^{5}$ we reported findings based on 5319 respondents in the nationwide health and lifestyle follow-up survey of 1991-92. This showed that women under 55 with a smoking history were more likely to report having suffered from arthritis/ rheumatism (OR 1.88 (95\% CI 1.39, 2.54)) as were men aged under 65 who were current smokers $(1.49(1.0,2.22))$. Furthermore, smoking was found to be associated with currently taking NSAIDS or drugs prescribed for analgesia (some of which have antiinflammatory properties). Analysis by logistic regression (age adjusted) of those aged 25-80 showed that men who were current smokers $(2.11(1.07,4.17))$ and women with a smoking history $(1.69(1.11,2.57))$ were more likely to be taking NSAIDS, and all smoking groups were significantly more likely than lifetime non-smokers to be taking NSAIDS and/or analgesics. There was also a dose effect, with those smoking 15 or more cigarettes a day the most likely to be taking these medications.

We hypothesise that the links between both arthritis and smoking, and NSAID/analgesic medication and smoking, suggest that the apparent protective effect of smoking against Alzheimer's disease could be due in part to the anti-inflammatory effects of these drugs. Those with a smoking history were more likely than those who had never smoked regularly to be taking these medications.

BRIAN D COX MARGARET J WHICHELOW Department of Community Medicine, Institute of Public Health, Cambridge CB2 $2 S R$

1 Prince M, Cullen M, Mann A. Risk factors for Alzheimer's disease and dementia: A casecontrol study based on the MRC elderly hypertension trial. Neurology 1994; 44: 97-104.

2 The Canadian Study of Health and Aging. The Canadian study of health and aging: risk factors for Alzheimer's disease in Canada. Neurology 1994; 44: 2073-80.

3 van Duijn C M, Hofman A. Relation between nicotine intake and Alzheimer's disease. $B M \mathcal{F}$ 1991; 302: 1491-4.

4 Brenner D E, Kukull W A, van Belle G et al Relationship between cigarette smoking and case-control study. Neurology 1993; 43; 293 300

5 Cox B D, Prevost A T, Whichelow M J. Associations of smoking with prescribed medications, arthritis/rheumatism and back problems in the British health and lifestyle survey follow-up respondents. Eur F Public Health; 1997; 7(3). In press.

\section{The evaluation of agreement on continuous variables by the intraclass correlation coefficient}

SIR-You published an interesting paper by Poulter et $a l^{1}$ on the reliability of data derived from proxy respondents in an international case-control study of cardiovascular disease and oral contraceptives. The agreement between the information obtained from "true" controls and their proxy respondents was evaluated thoroughly. Categorical data were evaluated using Kappa statistics. Comparisons between continuous variables were performed by means of the intraclass correlation coefficient (ICC). Nevertheless, detailed 
study of the paper has revealed that the referance between the continuous variables considered in the study is based contains a possible error.

The ICC is the proportion of total variability accounted for by the variability among subjects. A high ICC means that not much of ment on different occasions (proxy versus true control, in this case) or, what amounts to the same thing, that the agreement between them is high. ${ }^{2}$ The ICC for the common situation in which there are two observations for each subject can easily be calculated from an analysis of variance (ANOVA), as shown in the example in table 1 (formula 1 ). ${ }^{2}$ As the ANOVA may be somewhat burdensome to carry out, Deyo et al offered a simple method for calculating the ICC (see formula 2 in table 1).

The calculation of the ICC by Poulter $e t a l^{1}$ seems to be based on a commonly cited review article on statistics of concordance, which unfortunately omitted $n$ in the denominator of the original equation for ICC proposed by Bartko. ${ }^{3}$ Results based on this mistaken formula underestimate the observed agreement as shown in table 1 (formula 3).

Formulas 1 to 3 assume a random effects model. Another model must nevertheless be distinguished in making inferences about the factors affecting the measurements-the fixed effects model. ${ }^{2}$ In the random effects model, the two raters implied in the measurement are assumed to be a sample from a larger population of raters. In the fixed effect model, the two raters are the only raters about ence on which the calculation of the concordthe variability is due to variability in measure-

which inferences will be made. Although the calculation of ICC assuming a fixed effects model is also based on the ANOVA table, the formula is different (see formula 4 in table 1). Prieto et al have also proposed a simpler method for calculating the ICC in this case (see formula 5 in table 1).

The calculations of Poulter et al on the ICC assume a random effects model. Since proxy and "true" controls are the only raters about which inferences were made, we believe that it would be more correct to assume a fixed effects model. Nevertheless, more information concerning the selection of cases and "true" and proxy controls would be necessary to strengthen this hypothesis.

Since important differences in results may be obtained, future studies that consider the agreement of continuous variables must be extremely careful in selecting formulas to estimate the appropriate ICC.

LUIS PRIETO

ROSA LAMARCA

ALFONSO CASADO JORDI ALONSO

Health Services Research Unit, Institut Municipal d'Investigació Mèdica (IMIM), Dr Aiguader 80, E-08003 Barcelona, Spain

1 Poulter NR, Chang CL, Farley TMM, Marmot MG. Reliability of data from proxy respondents in an international case-control study of cardiovascular disease and oral contraceptives. 7 Epidemiol Community Health 1996;50:674-80.

2 Fleiss JL. The design and analysis of clinical experiments. New York: John Wiley \& Sons, $1986 ; 1-32$.

3 Deyo RA, Diehr P, Patrick DL. Reproducibility and responsiveness of health status measures. and responsiveness of health status measured Clinical Trials 1991;12:142s-58s.

Table 1 Estimation of agreement between two measures ( $A$ and $B$ ) through the intraclass correlation coefficient (ICC). Hypothetical data considering two measures in 10 patients

\begin{tabular}{llll}
\hline Subject & Measure $A$ & Measure B & Difference $(B-A)$ \\
\hline 1 & 75 & 80 & 5 \\
2 & 74 & 84 & 10 \\
3 & 76 & 81 & 5 \\
4 & 79 & 83 & 4 \\
5 & 82 & 92 & 10 \\
6 & 83 & 88 & 5 \\
7 & 85 & 90 & 5 \\
8 & 87 & 92 & 5 \\
9 & 87 & 92 & 5 \\
10 & 88 & 93 & 5.9 \\
Mean & 81.6 & 87.5 & 4.8 \\
SD $^{2}$ & 28.1 & 25.4 &
\end{tabular}

ANOVA table on preceding data

\begin{tabular}{llll}
\hline Source of variation & DF & SS & MS \\
\hline Between subjects (S) & 9 & 459.45 & 51.05 \\
Within patients (Measurements) (M) & 1 & 174.05 & 174.05 \\
Residual (R) & 9 & 21.45 & 2.38 \\
Total & 19 & 654.95 & \\
\hline
\end{tabular}

Formulas for the calculation of the ICC

\begin{tabular}{|c|c|c|}
\hline $\begin{array}{l}\text { Random effects } \\
\text { ICC Bartko }\end{array}$ & $10 \cdot(51.05-2.38)$ & (formula 1) \\
\hline & 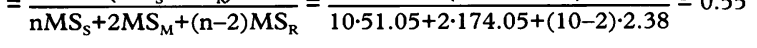 & \\
\hline ICC Deyo et a ${ }^{\beta}$ & $=\frac{\mathrm{SD}_{\mathrm{A}}^{2}+\mathrm{SD}_{\mathrm{B}}^{2}-\mathrm{SD}_{\mathrm{A}-\mathrm{B}}^{2}}{\mathrm{SD}_{\mathrm{A}}^{2}+\mathrm{SD}_{\mathrm{B}}^{2}=\dot{\mathrm{X}}_{\mathrm{A}-\mathrm{B}}^{2}-\mathrm{SD}_{\mathrm{A}-\mathrm{B}}^{2} / \mathrm{n}}=\frac{28.1+25.4-4.8}{28.1+=34.81-0.48}=0.55$ & (formula 2) \\
\hline $\begin{array}{l}\text { Icc Kramer and } \\
\text { Feinsten }^{4}\end{array}$ & $=\frac{\mathrm{MS}_{\mathrm{S}}-\mathrm{MS}_{\mathrm{R}}}{\mathrm{MS}_{\mathrm{S}}+2 \mathrm{MS}_{\mathrm{M}}+\mathrm{MS}_{\mathrm{R}}}=\frac{51.05-2.38}{\{51.05+2 \cdot 174.05+2.38}=0.12$ & (formula 3) \\
\hline $\begin{array}{l}\text { Fixed effects } \\
\text { ICC Fleiss }{ }^{2}\end{array}$ & $=\frac{\mathrm{n}\left(\mathrm{MS}_{\mathrm{S}}-\mathrm{MS}_{\mathrm{R}}\right\}}{\mathrm{nMS}_{\mathrm{S}}+\mathrm{MS}_{\mathrm{M}}+(\mathrm{n}-1) \mathrm{MS}_{\mathrm{R}}}=\frac{\{10 \cdot(51.05-2.38)}{10 \cdot 51.05+174.05+9 \cdot 2.38}=0.69$ & (formula 4) \\
\hline ICC Prieto et ap & $=\frac{\mathrm{SD}_{\mathrm{A}}^{2}+\mathrm{SD}_{\mathrm{B}}^{2}-\mathrm{SD}_{\mathrm{A}-\mathrm{B}}^{2}}{\mathrm{SD}_{\mathrm{A}}^{2}+\mathrm{SD}_{\mathrm{B}}^{2}+\overline{\mathrm{X}}_{2}+\mathrm{X} \mathrm{b}_{\mathrm{A}-\mathrm{B}}^{2} / 2-\mathrm{SD}_{\mathrm{A}-\mathrm{B}}^{2} / 2 \mathrm{n}}=\frac{28.1+25.4-4.8}{28.1+25.4+17.41-0.24}=0.69$ & (formula 5) \\
\hline
\end{tabular}

4 Kramer MS, Feinstein AR. Clinical biostatistics. IV. The biostatistics of concordance. Clin Phar macol Ther 1981;29:11-23.

5 Prieto L, Lamarca R, Casado A. La evaluación de la fiabilidad en las observaciones clínicas: $\mathrm{el}$ Coeficente de Correlación Intraclase. Med Clin (Barc). In press.

\section{Reply}

Dr Prieto et al are correct that the formula to calculate intraclass correlation coefficients (ICC) included in Kramer and Fenstein's review ${ }^{1}$ is misquoted and underestimates the observed agreement. However, while we included the reference to Kramer and Fenstein as background information on ICC, in our recent evaluation of the reliability of proxy-derived data in a case-control study ${ }^{2}$ we used the formula included in Bartko's original paper. ${ }^{3}$

We agree that the random or fixed effects model affects the estimated ICC and our choice of this random effect model is not ideal where raters were not necessarily representative of a larger population of raters. However, the ICC calculated using Bartko's formula ${ }^{3}$ do not differ importantly from those calculated using Prieto's formula, ${ }^{4}$ assuming a fixed effect model (table 1). The only three exceptions to this finding are for comparisons of true and proxy data when only two pairs are involved (mother/daughter and sister/ sister). In such a situation all estimates are unstable.

C L CHANG

T M M FARLEY

M MARMOT

N R POULTER

Department of Epidemiology and Public Health, University College London Medical School, London

1 Kramer MS, Fenstein AR. Clinical biostatics IV The biostatics of concordance. Clin Pharmaco Therap 1981;29:111-23.

2 Poulter NR, Chang CL, Farley TMM, Marmo MG for the World Health Organization Collaborative Study of Cardiovascular Disease and Steroid Hormone Contraception. Reliability of data from proxy respondents in an international case-control study of cardiovascula disease and oral contraceptives. 7 Epidemiol Community Health 1996;50(6):674-80.

Table 1 Comparison of ICC estimates using random and fixed effects models (comparisons relate to data shown in reference 2 )

\begin{tabular}{lll}
\hline & $\begin{array}{l}\text { Random } \\
\text { effects }\end{array}$ & $\begin{array}{l}\text { Fixed } \\
\text { effects }\end{array}$ \\
\hline Husband & & \\
Age & 1.00 & 1.00 \\
Weight & 0.90 & 0.89 \\
Height & 0.80 & 0.79 \\
Duration current OC & 0.98 & 0.98 \\
Duration last OC & 0.79 & 0.80 \\
Mother & & \\
Age & 1.00 & 1.00 \\
Weight & 0.99 & 0.96 \\
Height & 0.90 & 0.89 \\
Duration current OC & 0.52 & 0.63 \\
Duration last OC & 0.35 & 0.25 \\
Sister & & \\
Age & 1.00 & 1.00 \\
Weight & 0.96 & 0.97 \\
Height & 0.87 & 0.86 \\
Duration current OC & 0.03 & 0.47 \\
Duration last OC & 0.89 & 0.93 \\
All subjects & & \\
Age & 1.00 & 1.00 \\
Weight & 0.93 & 0.92 \\
Height & 0.83 & 0.82 \\
Duration current OC & 0.94 & 0.91 \\
Duration last OC & 0.77 & 0.75 \\
\hline OC o oral contraception & &
\end{tabular}


3 Bartko JJ. The intraclass correlation coefficient as a measure of reliability. Psychol Rep 1966;19: 3-11.

4 Prieto L, Lamarca R, Casado A. La evaluacion de la fiabilidad en las observaciones clinicas: el Coeficente de Correlacion Intraclase. Med Clin (Barc). In press.

\section{NOTICES}

European Journal of Public Healthvolume 7 (2) June 1997

\section{Editorial}

Balancing state and market in health system reform $R B$ Saltman

\section{Editorial note}

f Palm, P-G Svensson

\section{Original articles}

Use of provocative emotional appeals in a mass media campaign designed to prevent smoking among adolescents. $A$ Hafstad, $B$ Stray-Pedersen, $F$ Langmark

Managing the gap between demand and publicly affordable health care in an ethical way. $\mathcal{F} A$ Öretveit

Measuring performance in hospital care: length of stay in gynaecology. $A H$ Leyland, FA Boddy

Adolescent motherhood and socioeconomic factors: an ecologic approach. M Nebot, $C$ Borrell, $\mathcal{F} R$ Villalbi

Impaired cognitive function in elderly men exposed to benzodiazepines or other anxiolytics. F Ranstam, $\mathcal{F}$ Merlo, $G$ Blennow, $B S$ Hanson, P-O Östergren, $A$ Melander

Cost-effectiveness of vaccination against pneumococcal pneumonia in the Netherlands. $R M P M$ Baltussen, $A \mathcal{F} H A$ Ament, $R$ $M$ Leidl, $R$ van Furth

Sick-leave and disability pensions among female assembly workers. B Pålsson, $V$ Horstmann, $R$ G Attewell, K Ohlsson, S Skerfoing

\section{Cancer}

Trends in cancer mortality in central European countries: the effect of age, birth cohort and time-period. $T V$ Evstifeeva, $G \mathcal{F}$ Macfarlane, $C$ Robertson

Socioeconomic group, occupation and incidence of breast cancer and genital cancer among women in Denmark. B A Rix, T Skov, E Lynge

Compliance after 17 years of breast cancer screening: factors associated with reattendance for periodic breast screening. W ScafKlomp, F L P van Sonderen, $\mathcal{F} W A$ van den Heuvel

\section{AIDS/HIV}

Experience with and attitudes towards HIV patients among Italian general practitioners. A C Bosio, M Cesa-Bianchi

Public reactions to AIDS in Sweden: less anxiety, less risk taking. $C$ Herlitz, $A$ Strandell Intravenous drug users and AIDS: knowledge, attitudes and behaviour in Calabria, Italy. $M$ Pavia, $A$ Indovino, $C G A$ Nobile, $I F$ Angelillo

\section{Methods}

Severity measurement using a generic instrument: a feasibility study in ambulatory care involving patients with diabetes or asthma. $M$ Eccles, $N$ Steen, A Hutchinson, C Bradshaw, $E$ $\mathrm{McColl}$
The development of patient groupings for more effective management of health care. $H$ $F$ Sanderson, L M Mountney

The development of patient groupings for more effective management of health care: a comment. $\mathcal{F}$ Hofdijk

Assuming independence of risk factor prevalences in simulation models like PREVENT: when are the outcomes seriously biased? $P \mathcal{F}$ van de Mheen, L $\mathcal{f}$ Gunning-Schepers

\section{Commentaries}

Socioeconomic health differences: a commentary. $W W$ Holland Socioeconomic health differences: a reply. $L \mathcal{F}$ Gunning-Schepers, $A$ Gepkens

Perinatal and infant mortality: a worldwide issue: a commentary. C Akukwe

\section{Obituaries}

Book Reviews

Calendar of Events

\section{EUPHA pages}

Information for Authors

\section{6th Interntional Symposium on} Epidemiology and Occupational Risks, 22-24 April 1998, Graz, Austria.

International conference on the role and importance of epidemiological studies in the prevention of and compensation for occupational accidents and diseases. Further information: Allgemeine Unfallversicherungsanstalt, Office for International Relations and Conferences, Adalbert-Stifter-Strasse 65, A-1200 Vienna. Tel: +43133111537.

Fax: +43133111469.

email: presse@auva.or.at.

\section{CORRIGENDUM}

Weich $\mathrm{S}$ et al. Strategies for the prevention of psychiatric disorder in primary care in south London $(\mathcal{F}$ Epidemiol Community Health 1997;51:304-09). There is an error in the legend for figure 1 of this article. The legend for the upper line indicated by squares should read "Reduction of ICSA-11 score to 0 for all attenders", and that for the lower line should read " 1 point reduction in ICSA-11".

\section{BOOK REVIEWS}

Joint Approaches for a Better Old Age: Developing Services Through Joint Commissioning. Richard Poxton (Pp 56; £9.95). London: King's Fund, 1996. ISBN 1-85717-114-4.

Responding to the needs of older people probably remains the biggest challenge facing health and social care, to quote the author himself. This report examines the process of joint commissioning of services by health and local authorities in five contrasting local areas. Much of the work of the project has been recorded in a series of previous King's
Fund papers; the present report draws out the key lessons.

Monitoring the process of service development is a slippery task, especially when a multiplicity of agencies is involved. As the report acknowledges, significant changes will take time, often longer than an individual researcher is able to follow them. So here we have an account of work in process, rather than neatly defined historical episodes.

Poxton presents grounds for modest optimism. Achievements differ in the various localities, but rigorous evaluation of planning initiatives is seldom easy, and short term perspectives may be misleading. The qualities of vision and passion, here identified as essential, are particularly difficult to pin down.

One complication to the success of joint commissioning which the report neglects relatively is that of the different occupational settings of the participants. GPs often point out that social services departments have high staff turnover; their own positions are relatively stable, while allowing them considerable scope in deciding the margins of their job. In a primary care led NHS, their contribution to processes like joint commissioning will be increasingly influential.

$$
\begin{array}{r}
\text { BERNARD INEICHEN } \\
\text { Lecturer in Public Health } \\
\text { Charing Cross and Westminster Medical School, } \\
\text { London }
\end{array}
$$

Epidemiology in Old Age. S Ebrahim and A Kalache (eds). (Pp 436; £59.95) London: BMJ Publishing Group, 1996. ISBN 0-7279-0948-7.

Populations are ageing in almost every country, and this book begins to fill a large void in the literature of health in the elderly. There are 45 chapters with an impressive list of contributors. Two thirds are from the UK and the rest from eight different countries. Many are established authorities on their chosen subject. As Margot Jefferys says in her editorial preface, this should become a standard reference book.

Chapter subjects range well beyond consideration of individual diseases, to encompass, for example, health economics, community care, migration and ethnicity, and iatrogenesis. Its scope aims (and generally succeeds) in being truly international. The editors have succeeded in keeping contributors to a uniform chapter length of about nine pages. They have been less successful in achieving a universal standard of up to dateness. However, given the explosion of knowledge in the past decade, and the ease with which it can be retrieved, this is a serious point. There are dangers ahead too-volumes like this age quickly in matters of detail.

Nevertheless, Epidemiology in Old Age is a splendid achievement. The price is too steep for individuals, but medical libraries will find it of great value. It is extremely well produced with a vivid purple cover. Specialists will find their particular concerns examined in more detail elsewhere, but for those who want to venture into new aspects of geriatric epidemiology, their search begins here.

BERNARD INEICHEN

Lecturer in Epidemiology Charing Cross and Westminster Medical School, 